\title{
Stimulated electromagnetic emissions spectrum observed during an X-mode heating experiment at the European Incoherent Scatter Scientific Association
}

\author{
Xiang Wang ${ }^{1 *}$, Chen Zhou ${ }^{1 *}$, Tong $\mathrm{Xu}^{2}$, Farideh Honary ${ }^{3}$, Michael Rietveld ${ }^{4,5}$, and Vladimir Frolov ${ }^{6,7}$ \\ ${ }^{1}$ Department of Space Physics, School of Electronic Information, Wuhan University, Wuhan 430072, China; \\ ${ }^{2}$ National Key Laboratory of Electromagnetic Environment, China Research Institute of Radiowave Propagation, Qingdao 266107, China; \\ ${ }^{3}$ Department of Physics, Lancaster University, Lancaster LA1 4YB, UK; \\ ${ }^{4}$ EISCAT Scientific Association, N-9027 Ramfjordmoen, Norway; \\ 5Institute for Physics and Technology, UiT The Arctic University of Norway, N-9037, Tromsø, Norway; \\ ${ }^{6}$ Radiophysical Research Institute, Nizhny Novgorod 603600, Russia; \\ ${ }^{7}$ Kazan Federal University, Kazan 420008, Russia
}

\begin{abstract}
An extraordinary (X-mode) electromagnetic wave, injected into the ionosphere by the ground-based heating facility at Troms $\varnothing$, Norway, was utilized to modify the ionosphere on November 6, 2017. The high-power high-frequency transmitter facility located at Tromsø belongs to the European Incoherent Scatter Scientific Association. In the experiment, stimulated electromagnetic emission (SEE) spectra were observed. A narrow continuum occurred under cold-start conditions and showed an overshoot effect lasting several seconds. Cascading peaks occurred on both sides of the heating frequency only in the preconditioned ionosphere and also showed an overshoot effect. These SEE features are probably related to the ponderomotive process in the X-mode heating experiment and are helpful for understanding the physical mechanism that generated them during the X-mode heating experiment. The features observed in the $\mathrm{X}$-mode heating experiments are novel and require further investigation.
\end{abstract}

Keywords: artificial ionosphere modification; stimulated electromagnetic emissions; extraordinary electromagnetic wave; European Incoherent Scatter Scientific Association (EISCAT)

Citation: Wang, X., Zhou, C., Xu, T., Honary, F., Rietveld, M., and Frolov, V. (2019). Stimulated electromagnetic emissions spectrum observed during an X-mode heating experiment at the European Incoherent Scatter Scientific Association. Earth Planet. Phys., 3(5), 391-399. http://doi.org/10.26464/epp2019042

\section{Introduction}

A ground-based heating facility transmits high-power high-frequency (HF) electromagnetic (EM) waves into the ionosphere, resulting in a great number of phenomena, including large-scale electron temperature and density changes (Robinson, 1989), HFenhanced plasma lines and ion lines (Blagoveshchenskaya et al., 2014, 2015; Kuo, 2015; Wang X et al., 2016; Wang X and Zhou C, 2017), enhanced airglow (Kosch et al., 2007; Blagoveshchenskaya et al., 2014), Langmuir turbulence (Stubbe et al., 1992; Gurevich et al., 2004), and artificial field-aligned irregularities (FAls; Grach and Trakhtengerts, 1975; Kelly et al., 1995; Blagoveshchenskaya et al., $2011,2015)$. The heating wave may also generate secondary EM waves, termed stimulated electromagnetic emissions, or SEEs. The SEEs were discovered by Thidé et al. (1982) and have been re-

Correspondence to: X. Wang, wangxiang.whu@whu.edu.cn

$$
\text { C. Zhou, chenzhou@whu.edu.cn }
$$

Received 19 MAR 2019; Accepted 08 JUL 2019.

Accepted article online 26 JUL 2019.

C 2019 by Earth and Planetary Physics. viewed by Leyser (2001).

The SEE spectra generated by ordinary (O-mode) polarized EM waves have been studied extensively in the past several decades at different heating facilities, such as those in Troms $\varnothing$, Norway (Stubbe et al., 1984, 1994; Leyser et al., 1990; Fu et al., 2015), in Russia (Leyser et al., 1993; Frolov et al., 1999, 2001; Sergeev et al., 2006), at the High Power Auroral Stimulation Observatory (HIPAS) in Fairbanks, Alaska (Armstrong et al., 1990; Cheung et al., 1997), at the High-Frequency Active Auroral Research Program (HAARP) in Gakona, Alaska (Bernhardt et al., 2011), and in Arecibo, Puerto Rico (Thidé et al., 1989, 1995). In past decades, researchers have reported many features of the SEE spectra and their generation mechanisms. Stubbe et al. (1984) introduced several features of SEE spectra, including the "downshifted maximum" (DM) and "upshifted maximum" (UM), which are downshifted and upshifted from the heating frequency $f_{0}$ by approximately $9-15 \mathrm{kHz}$, respectively; the 2DM or 3DM, which are 2 or 3 times the frequency shifts of the DM; and the "downshifted peak" (DP) and "upshifted peak" (UP), which are peaks at $1-3 \mathrm{kHz}$ below or above $f_{0}$. Leyser et al. (1993) separated the continuum spectra into a broad con- 
tinuum (BC), which extends up to $60-120 \mathrm{kHz}$ on the downshifted side of the heating frequency $f_{0}$, and a narrow continuum (NC), which exists in the frequency range between the DM and $f_{0}$ and presents a swift decrease in intensity with an increasing frequency offset. According to investigations of the temporal evolution of SEE features, the NC can be further separated into a ponderomotive NC (NC by Frolov et al., 2004, or FNC by Leyser, 2001), which is produced by a ponderomotive nonlinearity, and a thermal NC ( $\mathrm{NC}_{\text {th }}$ by Frolov et al., 1997, or SNC by Leyser, 2001), which is related to a thermal parametric instability.

Most of the reported SEE spectra have been observed during Omode heating experiments, and only a few observations have been made during X-mode heating experiments. Thidé et al. (1983) observed narrow peaks that formed a banded structure in the upshifted sideband in an X-mode heating experiment with a heating wave frequency $f_{0}$ of $2.759 \mathrm{MHz}$. Sharma et al. (1993) suggested the SEE spectra observed during the X-mode heating period reported by Thidé et al. (1983) were the result of a parametric decay instability (PDI). They showed that the X-mode EM wave could parametrically decay to an upper hybrid wave and a lowfrequency electrostatic ion-Bernstein wave at different gyroharmonics. In the X-mode heating experiments carried out on October 21, 2012, and October 27, 2013, at Tromsø, Norway, Blagoveshchenskaya et al. (2015) reported that narrow SEE spectra had been observed at Saint Peterburg, Russia (1,200 km away from the EISCAT heating facility), accompanied by SEE spectra within 200 $\mathrm{kHz}$ observed at Troms $\varnothing$. The frequency of narrowband SEE spectral components was within $1 \mathrm{kHz}$ of the HF heating frequency, and these components were considered stimulated Brillouin scattering (Bernhardt et al., 2011; Fu et al., 2015). Blagoveshchenskaya et al. (2015) also reported that a narrow SEE spectral component was observed during the period when HF-enhanced ion lines were observed by the EISCAT ultra high frequency (UHF) radar in the X-mode heating experiment. These results suggested that the narrow SEE spectra may be associated with the ion acoustic wave, electrostatic ion cyclotron wave, and electrostatic ion cyclotron harmonic wave. Blagoveshchenskaya et al. (2017a) demonstrated experimental results on the behavior and intensities of various spectral lines in the narrowband SEE spectra within $1 \mathrm{kHz}$ of the heater frequency, depending on the pump frequency stepping across the fifth electron gyroharmonic frequency observed far away from the heater frequency. Blagoveshchenskaya et al. (2018) analyzed in detail the narrowband SEE spectral features in the course of the X-mode experiment on February 25, 2013, at a pump frequency of $5.423 \mathrm{MHz}$ at Saint Peterburg, which is 1,200 km away from Tromsø. However, Blagoveshchenskaya et al. (2015, 2017a, 2018) did not observe any spectral features within $200 \mathrm{kHz}$ near Troms $\varnothing$ that were associated with X-mode heating near the fourth gyroharmonic frequency.

This article presents unique experimental observations of the SEE spectral components during an X-mode heating experiment performed on November 6, 2017, at the EISCAT heating facility at Tromsø, Norway. In Section 2, the experimental facilities and observations are briefly introduced. During the X-mode heating experiment, NC spectra, peaks at $\pm 5.127 \mathrm{kHz}$, and cascading peaks on both sides of the heating wave frequency were observed. The observed SEE spectra are discussed further in Section 3, and the principal conclusions are summarized in Section 4.

\section{Experimental Observations}

The experiment reported here was performed on November 6, 2017 , at the heating facility near Troms $\varnothing$, Norway $\left(69.59^{\circ} \mathrm{N}\right.$, $19.21^{\circ} \mathrm{E}$ ), which is run by the EISCAT Scientific Association (Rietveld et al., 1993, 2016). The experiment began at 11:30 UT with a 15- min transmission cycle of $10 \mathrm{~min}$ on and $5 \mathrm{~min}$ off. The heating frequency was $5.423 \mathrm{MHz}$, just below $4 f_{\text {ce, }}$ using high-gain array 1 with a beam inclination of $12^{\circ}$ and $6^{\circ}$, where $f_{\text {ce }}$ is the electron gyrofrequency. The difference between the heating waves $f_{0}$ and $4 f_{\text {ce }}$ was approximately $45 \mathrm{kHz}$. The period for each incident angle was $30 \mathrm{~min}$, or two transmission cycles. The polarization of the heating wave was set as the X-mode EM wave. All 12 transmitters were used at a nominal $80 \mathrm{~kW}$ each, resulting in a gain of 27.4 $\mathrm{dB}$ and an effective radiated power of approximately $450 \mathrm{MW}$.

The SEE receiver was an Ettus Research USRP N210 instrument fitted with a global positioning system (GPS) disciplined oscillator to provide the precise time and frequency. It was installed in the Troms $\varnothing$ suburb of Kroken, Norway $\left(69.68^{\circ} \mathrm{N}, 19.07^{\circ} \mathrm{E}\right)$, about $12 \mathrm{~km}$ north-northwest of the heating array. A mountain separates the receiver from the heating transmitter. The antenna of the SEE receiver was a Wellbrook active loop antenna of $1 \mathrm{~m}$ diameter. The sampled data were processed with the fast Fourier transform algorithm to yield SEE spectra with a frequency resolution of approximately $244.14 \mathrm{~Hz}$.

The EISCAT UHF radar was used to measure the plasma parameters in the ionosphere, such as the electron density and electron temperature, from $50 \mathrm{~km}$ to approximately $700 \mathrm{~km}$, with a $5 \mathrm{~s}$ time resolution. The plasma parameters were calculated from the EISCAT UHF radar spectra with the Grand Unified Incoherent Scatter Design and Analysis Package (Lehtinen and Huuskonen, 1996). A Dynasonde, co-located with the Troms $\varnothing$ heating facility, measured the ionogram at intervals of 2 min (Vicker, 2011). The ionogram provided the critical frequency of the ionospheric layers, the maximum plasma frequencies of the different ionospheric layers, and the maximum heights of the different ionospheric layers. Figure 1 illustrates the ionospheric parameters measured by the UHF radar and the critical frequency of the $F_{2}$ layer as measured by the Dynasonde HF sounder at Troms $\varnothing$ from 11:25 UT to 12:00 UT. These included the electron density (Figure 1a), the electron temperature (Figure $1 \mathrm{~b}$ ), the raw electron density (radar echo power profile; Figure 1c), and the critical frequency of the $F_{2}$ layer (Figure $1 \mathrm{~d}$ ). Figure $1 \mathrm{~b}$ shows that the electron temperature was enhanced by approximately $300-500 \mathrm{~K}$ in the range of $150-300$ $\mathrm{km}$ during the heating periods. In Figure $1 \mathrm{a}$ and $1 \mathrm{c}$, the electron density and the raw electron density did not show a considerable change during the heating cycles. As shown in Figure $1 \mathrm{~d}$, the heating wave frequency was higher than $f_{\mathrm{O}} \mathrm{F}_{2}$, which indicates that an O-mode wave penetrated the ionosphere during the two heating periods. The frequency of the $\mathrm{X}$-mode heating wave was lower than $f_{X} F_{2}$ in most of the heating cycles, except from 11:34 to 11:38 UT. Although the EISCAT heating facility was unable to produce a perfect O-mode or X-mode wave, any O-mode heating effect could be excluded because of the lower $f_{\mathrm{O}} \mathrm{F}_{2}$, which was lower 


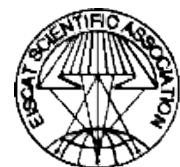

\section{EISCAT Scientific Association EISCAT UHF RADAR}
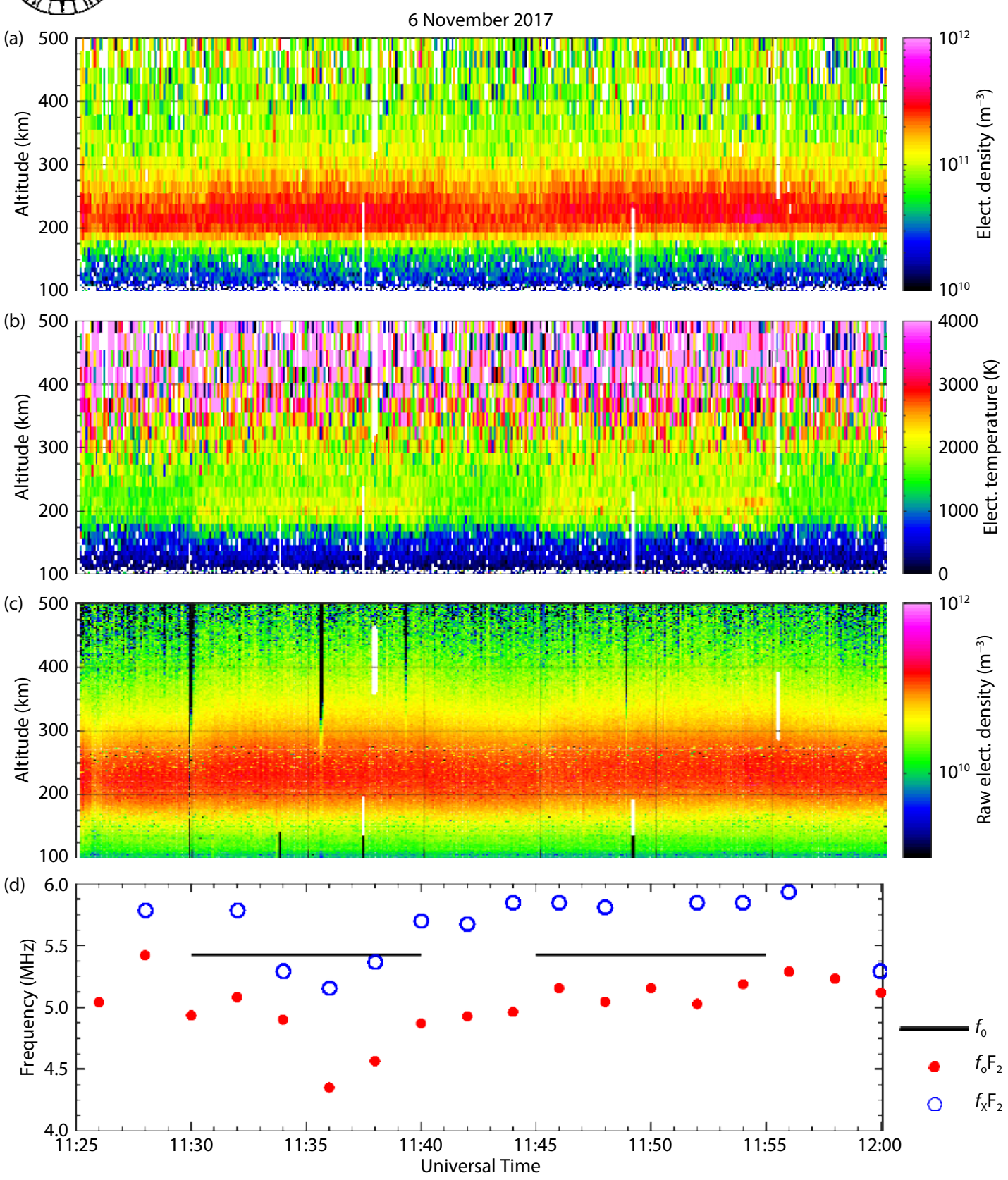

Figure 1. Parameters observed by the EISCAT UHF radar with a $5 \mathrm{~s}$ time resolution in the X-mode heating experiment at 11:25-12:00 UT on November 6, 2017: (a) electron density, (b) electron temperature, (c) raw electron density (backscattered power), (d) $f_{\mathrm{O}} \mathrm{F}_{2}$ and $f_{\mathrm{X}} \mathrm{F}_{2}$ detected by the Dynasonde at Tromsø, Norway. The heating experiment began at 11:30 UT, and the heater operated with a cycle of $10 \mathrm{~min}$ on and $5 \mathrm{~min}$ off.

than both the heating wave frequency and the upper hybrid frequency.

Figure 2 illustrates the observed spectrogram of the heater signal within $200 \mathrm{kHz}$ at 11:30-12:28 UT, in which the pump wave frequency was higher than $f_{\mathrm{O}} \mathrm{F}_{2}$. As shown in Figure $2 \mathrm{a}$, the incident angle of the heating wave was $-12^{\circ}$ (pointed to the geomagnetic field) at 11:30-11:55 UT. Figure 1b presents the SEE spectra observed at 12:00-12:25 UT with an incident angle of $-6^{\circ}$. SEE spectra around $f_{0}$ within $\pm 5 \mathrm{kHz}$ was clearly observed in the four heat- ing cycles under two different incident angles. As shown in Figure 2, the intensity of spectral components in the SEE spectra reached approximately $10 \mathrm{~dB}$. The SEE spectra disappeared at around 12:34 UT as the X-mode critical frequency dropped below the heater frequency.

Figure 3a-f presents observations of the SEEs in the first $5 \mathrm{~s}$ of the first heating cycle, i.e., from 11:30:00 to 11:30:05 UT. Figure 3a shows that two peaks occurred at $+5.127 \mathrm{kHz}$ and $-5.127 \mathrm{kHz}$ from the heating frequency $f_{0}$. Figure $3 \mathrm{~b}$ indicates that the intens- 

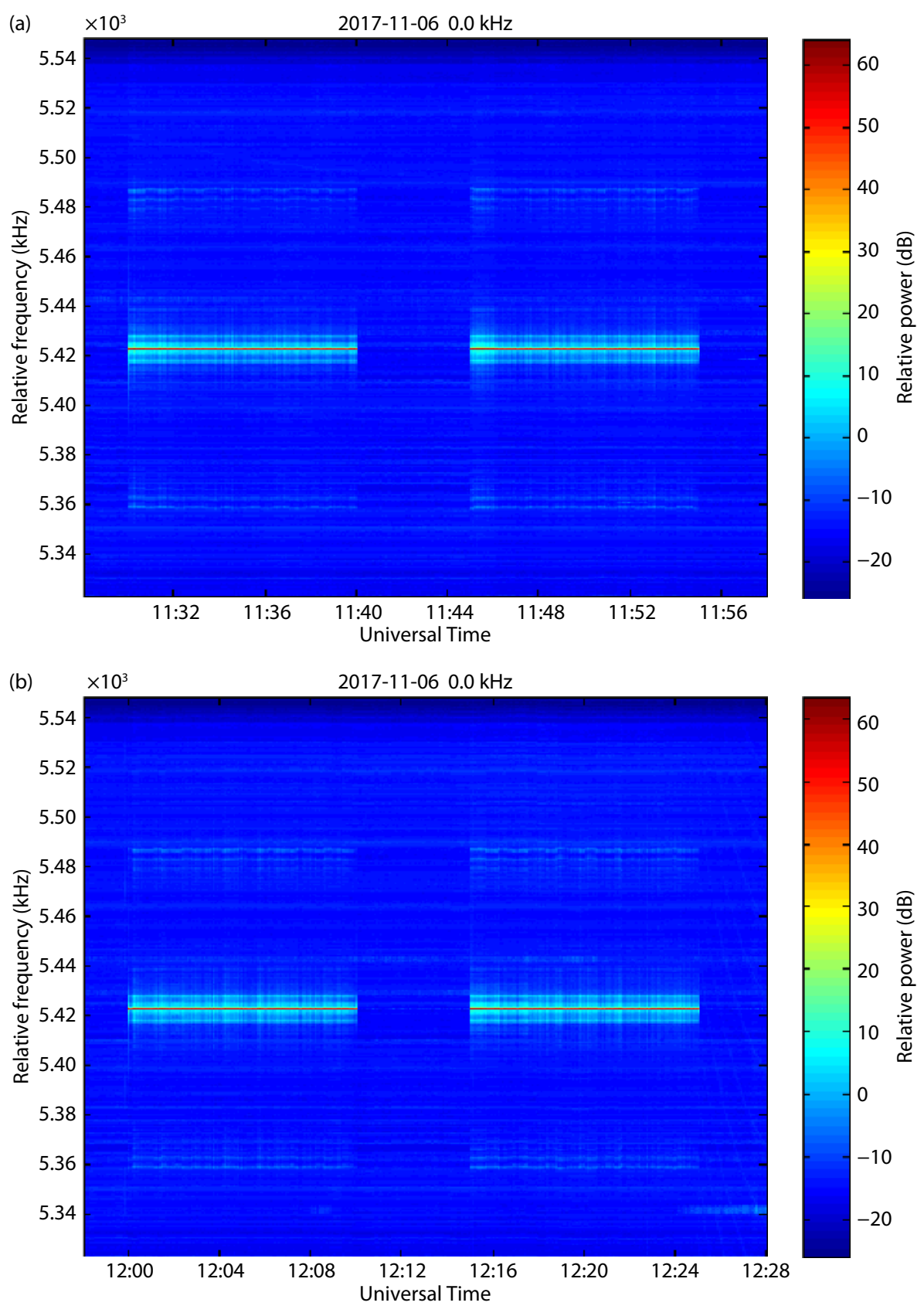

Figure 2. Spectrogram of the stimulated electromagnetic emission (SEE) within the $200 \mathrm{kHz}$ frequency band during the $X$-mode heating experiment on November 6,2017 . (a) with an incident angle of $-12^{\circ}$ at 11:30-11:55 UT and (b) with an incident angle of $-6^{\circ}$ at $12: 00-12: 25$ UT.

ity of the peaks at $f_{0}$ of $\pm 5.127 \mathrm{kHz}$ reached approximately $10 \mathrm{~dB}$ at 11:30:01 UT. Figure 3c-f presents the time evolution of the SEE, which indicates the evolution of the NC. The NC is a continuous spectrum that occurs only on the downshifted side of the pump frequency $f_{0}$, usually in the frequency range between the DM and the pump frequency. It showed a swift decrease in intensity with an increasing frequency offset (Leyser et al., 1993; Frolov et al., 1997). Figure 3c-e clearly show the NC spectra on the downshifted side of the heating wave frequency $f_{0}$, from approximately -25 to $-5 \mathrm{kHz}$.

Figure 4a-f illustrate SEE spectra in the first $5 \mathrm{~s}$ of the second heating cycle from 11:45:00 to 11:45:05 UT on November 6, 2017. Figure 4 a exhibits only the reflected heating wave at $f_{0}$. The peaks at $f_{0}$ of $\pm 5.127 \mathrm{kHz}$ are illustrated in Figure $4 \mathrm{~b}-\mathrm{f}$. A series of cascading peaks appear on both sides of the heating wave frequency at 11:45:03 and 11:45:04 UT in Figure 4d and 4e. The cascading peaks disappear thereafter at 11:45:05 UT, as shown in Figure 4f.

Figure $5 a$ illustrates the variation in intensity of the spectral peaks at $\pm 5.127 \mathrm{kHz}$ with respect to time during the heating period, in which the red and blue solid lines represent the spectra at -5.127 and $+5.127 \mathrm{kHz}$, respectively. The spectral peaks at $\pm 5.127 \mathrm{kHz}$ were sharply enhanced as the heater was turned on and were maintained throughout the 10-min heating cycle. The intensity of the spectral peaks was highly symmetrical in the heating period, except for the first several seconds. Both peaks illustrated an overshoot in intensity within the first $5 \mathrm{~s}$ of the heating period. In addi- 
(a) 11:30:00 UT

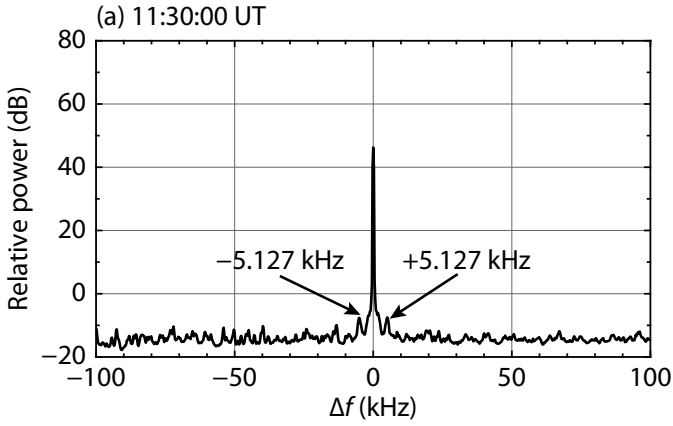

(c) 11:30:02 UT

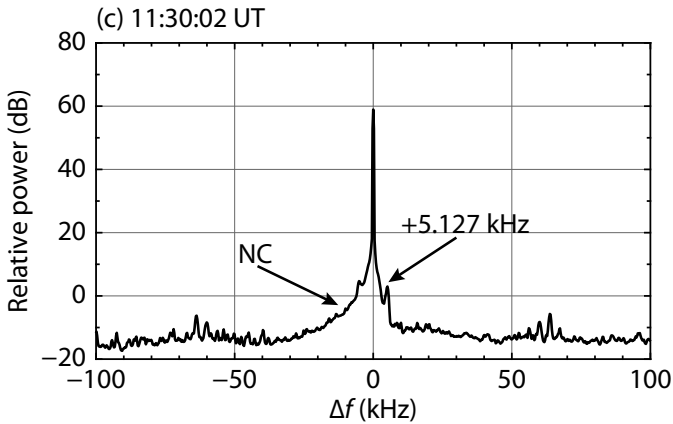

(e) 11:30:04 UT

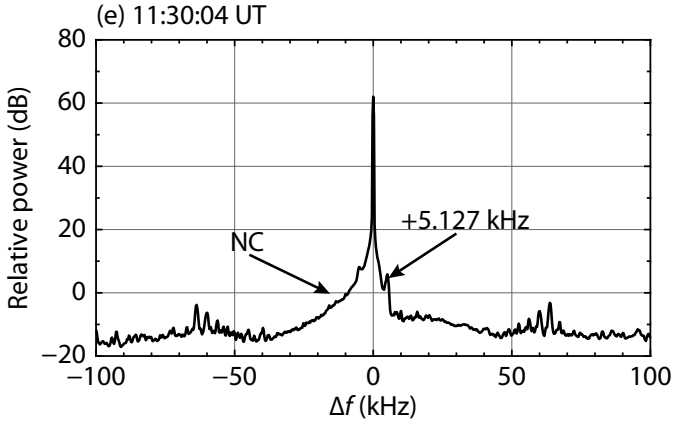

(b) 11:30:01 UT



(d) 11:30:03 UT
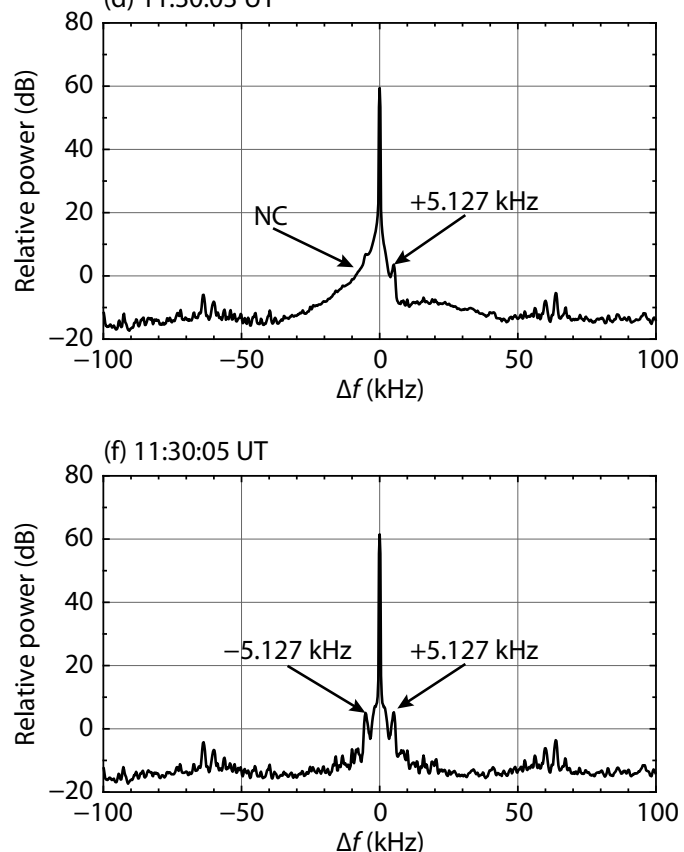

Figure 3. Intensity of the SEE spectra at (a) 11:30:00 UT, (b) 11:30:01 UT, (c) 11:30:02 UT, (d) 11:30:03 UT, (e) 11:30:04 UT, and (f) 11:30:05 UT. The horizontal axis presents frequency shifts of the SEE spectral component from the heating wave frequency. Zero frequency is the heating wave frequency, $f_{0}=5.423 \mathrm{MHz}$. NC, narrow continuum.

tion, the intensity of the DP remained higher than that of the UP throughout the heating period. Figure $5 \mathrm{~b}$ illustrates the temporal variation of the spectral intensity at five different frequencies picked up from the NC spectra, with the different colors representing different frequencies. The horizontal axis marks the time after heater turn-on. As shown in Figure 5, the intensity of the NC spectrum decreased with the frequency offset. The spectra at all frequencies increased with time in the first $3 \mathrm{~s}$ and then decreased to the noise level at $5 \mathrm{~s}$ after heater turn-on. The NC spectrum showed an overshoot effect, which is a prominent emission intensity maximum at a finite time after heater turn-on. A similar observation of NC development was reported by Leyser (2001) during $\mathrm{O}$-mode heating experiments. Figure $5 \mathrm{c}$ illustrates the temporal variation in the intensity of the cascading peaks, with the different colors representing different frequencies. As shown in Figure $5 c$, the intensity of the cascading peaks reached a maximum $3 \mathrm{~s}$ after heating and then decayed to the noise level within $5 \mathrm{s.}$

In comparing Figure 3 with Figure 4, it can be deduced that the NC spectra were generated only with the cold start (i.e., without a previous heating period), whereas the cascading spectra were observed in the preconditioned ionosphere (i.e., in the second heating cycle). Both the NC spectra and the cascading spectral peaks show an overshoot effect, as illustrated in Figure $5 \mathrm{~b}$ and $5 \mathrm{c}$. The two spectral peaks at $f_{0}$ of $\pm 5.127 \mathrm{kHz}$ remained throughout the heating period, as shown in Figure $5 \mathrm{a}$.

\section{Discussion}

SEEs are a crucial tool for investigating the nonlinear plasma response to an EM HF heating wave because the SEE spectra are sensitive to various wave-plasma interactions and they cover both short- and long-timescale nonlinear processes (Leyser, 2001; Frolov et al., 2004). Features of SEEs have been studied under different pump-plasma interaction conditions, such as spectral behavior in response to different heating wave frequencies (Stubbe et al., 1994), the heating power (Frolov et al., 2004), and pumping by additional waves (Stubbe et al., 1985). In addition, different SEE features have been utilized for studies of short-timescale ponderomotive nonlinear processes, such as Langmuir turbulence (Frolov et al., 2004), and long-timescale thermal nonlinear pro- 

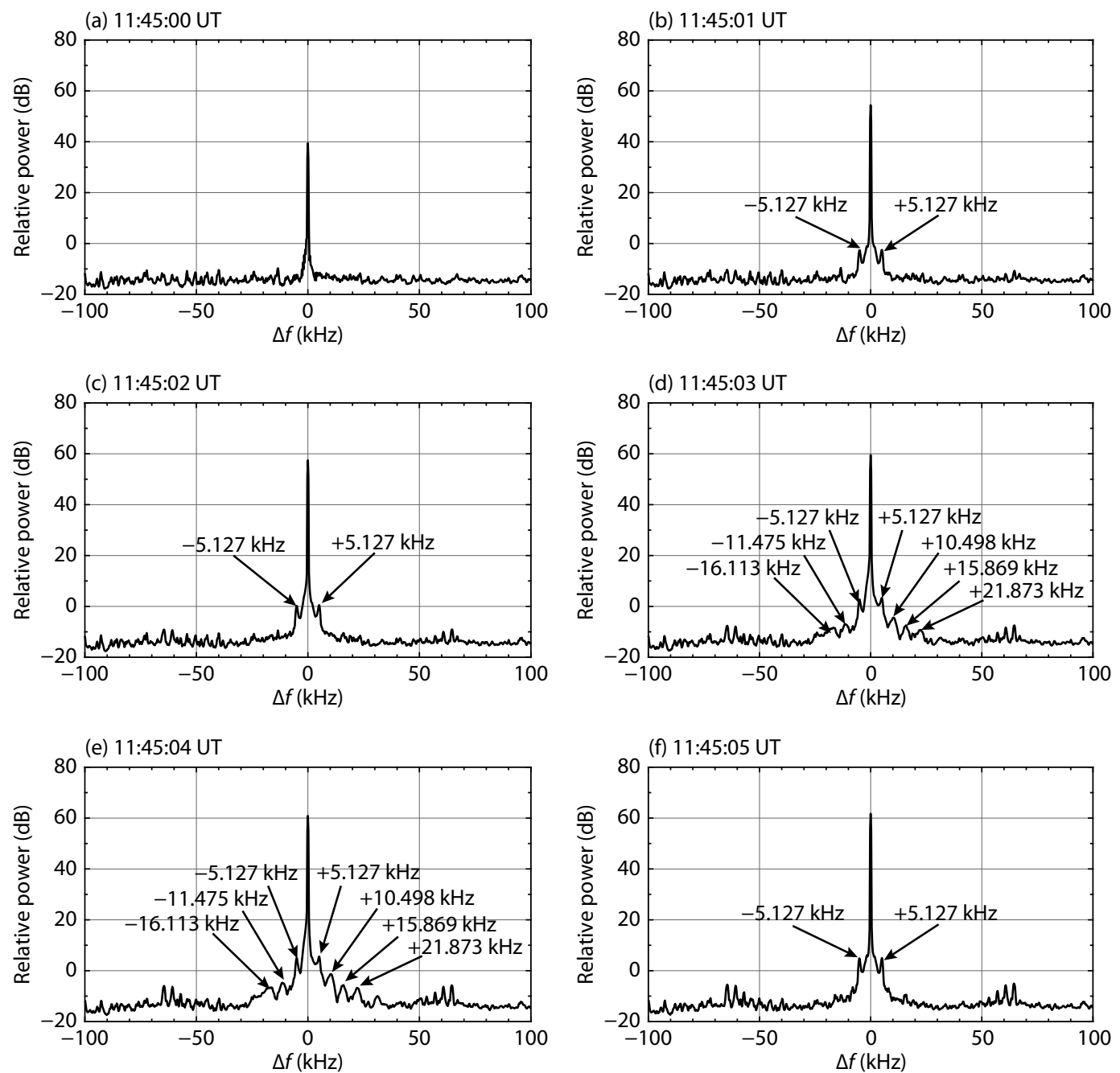

Figure 4. Intensity of the SEE spectra at (a) 11:45:00 UT, (b) 11:45:01 UT, (c) 11:45:02 UT, (d) 11:45:03 UT, (e) 11:45:04 UT, and (f) 11:45:05 UT. The horizontal axis presents frequency shifts in the SEE spectral component from the heating wave frequency. Zero frequency is the heating wave frequency, $f_{0}=5.423 \mathrm{MHz}$.

cesses, such as the excitation of FAls (Stubbe and Hagfors, 1997; Leyser, 2001). Provided the physical mechanism generating the SEE component is identified, information on the background ionospheric plasma and on nonlinear processes can be deduced by observing the variation in SEE features and the evolution of SEEs under different experimental conditions.

In Figure 3, the NC feature shows the overshoot effect for a cold start, i.e., without a previous heating wave. Figures 3 and $5 \mathrm{~b}$ show that the NC feature occurred $2 \mathrm{~s}$ after pump-on and was quenched $2 \mathrm{~s}$ later. The intensity of the NC spectrum decreased with the frequency offset. The intensity of the NC spectrum at each frequency gradually increased to the maximum and decreased to the noise level within $5 \mathrm{~s}$. In previous O-mode heating experiments, the ponderomotive NC was suggested to be the only spectral feature generated for a cold start (Leyser, 2001). It was found to be excited in intensity within a few milliseconds after heater turn-on for a cold start, and it exhibited an overshoot within 10 ms after the heater was switched on (Boiko et al., 1985). The ponderomotive NC was attributed to the development of the PDI below the heating wave reflection height (Frolov et al., 1997,
2004). In the O-mode heating experiments, the typical timescale of PDI excitation was several milliseconds (Robinson, 1989). Frolov et al. (2004) reported that in an O-mode heating experiment, the intensity of the ponderomotive NC increased rapidly, reached a maximum in the time interval of 2-10 ms after heater turn-on, and decayed from approximately 0.7 to $4-5 \mathrm{~ms}$. Compared with the ponderomotive $\mathrm{NC}$ feature in O-mode heating experiments, the timescale of NC development was much longer in the X-mode heating experiment reported here. In X-mode heating experiments, the PDI was excited for several seconds and even minutes (Blagoveshchenskaya et al., 2017b; Wang X et al., 2018). This conclusion was reached by observing the temporal evolution of the HF-enhanced plasma lines and ion lines, both of which are signatures of PDI excitation in ionospheric heating experiments. As shown in Figures 3 and 5b, the NC was still generated for a cold start and exhibited an overshoot effect. Thus, the NC observed in the $\mathrm{X}$-mode heating experiment may possibly be related to the PDI.

Figure 4a illustrates that the heating wave intensity at 11:45:00 UT was lower by $7 \mathrm{~dB}$ than its intensity level in the first cycle shown in 

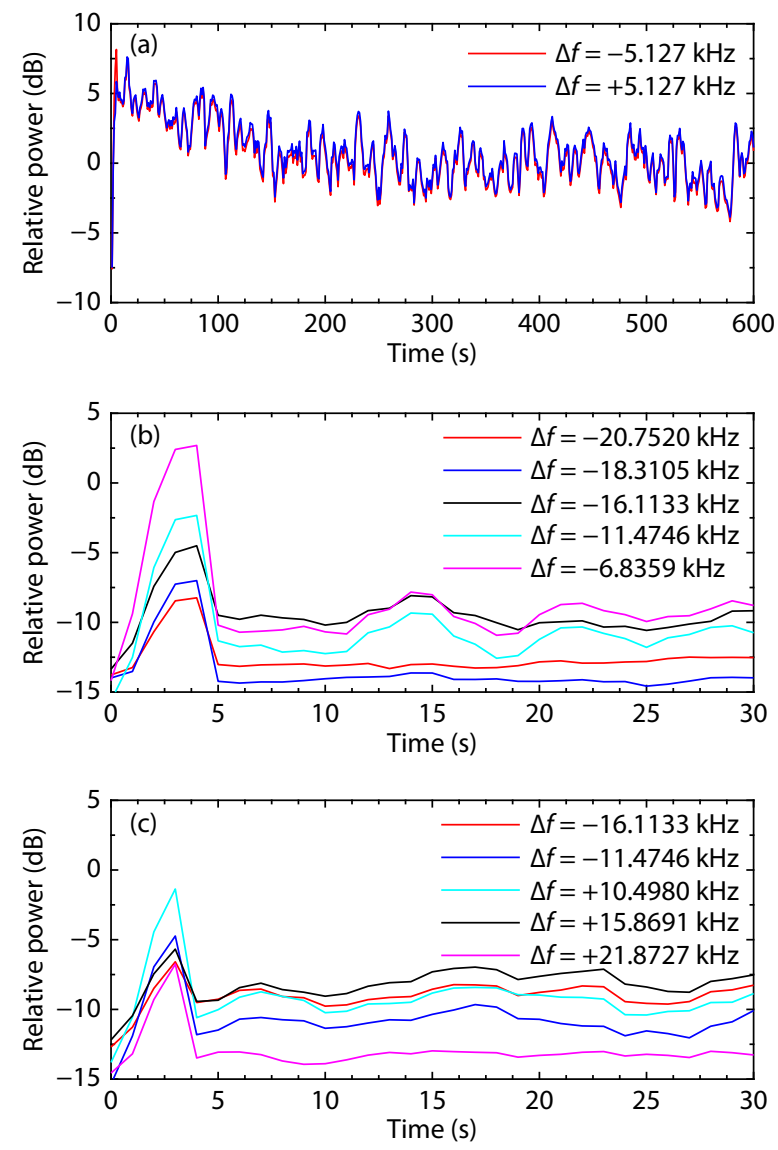

Figure 5. (a) Intensity variation of the peaks at $\pm 5.127 \mathrm{kHz}$ with respect to time. (b) Intensity variation of the five frequencies from the narrow continuum (NC) with respect to time. (c) Intensity variation of the five cascading peaks with respect to time, where the time resolution is $1 \mathrm{~s}$ and the different colors represent different frequencies.

Figure 3a. Furthermore, the cascading peaks in Figure 4 occurred only in the preconditioned ionosphere. The cascading peaks in Figures 4 and $5 c$ also exhibited an overshoot effect. It is possible that the cascading peaks may be related to the FAls induced by the heating wave. Field-aligned irregularities have been observed during X-mode heating experiments at Tromsø, Norway (Blagoveshchenskaya et al., 2011, 2014, 2015). Borisov et al. (2018) suggested using a two-step process to interpret the formation of 10$m$ FAls by the $X$-mode heating wave at high latitudes. The first step is the thermal self-focusing instability, and the second step is the formation of electron inhomogeneities resulting from the thermal self-focusing instability or from the gradient drift and current convective instabilities. Otherwise, it should be noted that small-scale FAls were not excited when powerful X-mode waves were used for pumping at the Sura facility, which is in the middle latitudes (Frolov et al., 2014).

The peaks at $f_{0}$ of $\pm 5.127 \mathrm{kHz}$ occurred symmetrically on both sides of the heating wave $f_{0}$ and were present during the entire 10-min heating cycle, as shown in Figures 3, 4, and 5a. However, in O-mode heating experiments, the DP/UP usually occurred at about -1 to $3 \mathrm{kHz}$, and the DM/UM often appeared at about 9 to $15 \mathrm{kHz}$ (Leyser, 2001; Frolov et al., 2004). The DP and UP are sym- metrical features around $f_{0}$ (Stubbe et al., 1994; Leyser, 2001). The broad symmetrical structure has been observed to be symmetrically excited at $f_{0}$ of approximately \pm 15 to $30 \mathrm{kHz}$, which has been recorded only slightly above $3 f_{\text {ce }}$ (Stubbe et al., 1994). Lobachevsky et al. (1992) observed an anticorrelation of the SEE spectra at $f_{0}$ of $\pm 5 \mathrm{kHz}$ for approximately $f_{0}$ to $3 f_{\text {ce }}$ on a time scale of several seconds in an O-mode heating experiment performed at Troms $\varnothing$, Norway. Compared with the SEE spectra observed in the O-mode heating experiment, the persistent feature of the peaks at $f_{0}$ of $\pm 5.127 \mathrm{kHz}$ was novel in the $\mathrm{X}$-mode heating experiment. Fejer and Leer (1972) showed that the electron Bernstein mode associated with FAls may be excited parametrically by an X-mode heating wave at a multiple gyrofrequency near the X-mode heating wave reflection height. This is a ponderomotive process that should occur rapidly after the heater is turned on. The peak at $f_{0}$ of $\pm 5.127 \mathrm{kHz}$ may be the excited electron Bernstein wave scattering off the FAls or low hybrid waves.

The presence of SEE spectra during the X-mode heating cycle is a large unexplored research area (Leyser, 2001). The physical mechanisms that generated the observed SEE spectra, including the NC spectra, the peaks at $\pm 5.127 \mathrm{kHz}$, and the cascading peaks, are not clear. This implies that more experiments need to be performed to investigate the SEE features in X-mode heating experiments in the future, as well as further theoretical development to explain them.

\section{Summary}

Stimulated electromagnetic emissions spectra for O-mode heating experiments have been extensively investigated since the 1980s, whereas SEE spectra in X-mode heating experiments have rarely been studied because of the limited observations of SEE during X-mode heating. This report presents unique SEE observations made during an X-mode heating experiment on November 6 , 2017, at the EISCAT heating facility in Tromsø, Norway. The heating wave frequency in the experiment was close to the fourth electron gyroharmonic frequency. The experimental observations illustrated NC spectra, peaks at $\pm 5.127 \mathrm{kHz}$, and cascading peaks on both sides of the heating wave frequency. Novel SEE features were observed in the X-mode heating experiment. The NC spectra and the cascading peaks presented an overshoot effect, and the peaks at $\pm 5.127 \mathrm{kHz}$ remained during the entire heating cycle. The intensity of the heating wave in Figures $2 \mathrm{a}$ and $5 \mathrm{a}$ indicated that the NC was observed only for the cold start and that the cascading peaks were observed only for the preconditioned ionosphere. The CUTLASS HF coherent radar, which can detect decameter-scale FAls above Tromsø, was operating in a nonoptimal mode and frequency $(12-12.5 \mathrm{MHz})$ during this experiment but nevertheless detected weak heat-induced backscatter (T. Yeoman, personal communication), although this observation was too poor for a detailed correlation with the SEE spectra. This result implies that more experiments are needed to investigate the SEE components generated by the $\mathrm{X}$-mode heating wave in the future.

\section{Acknowledgments}

EISCAT is an international scientific association supported by research organizations in China (China Research Institute of Radiowave Propagation), Finland (Suomen Akatemia, SA), Japan (Na- 
tional Institute of Polar Research), Norway (Norges forskningsråd), Sweden (Vetenskapsrådet), and the United Kingdom (UK Research and Innovation). This work was supported by the National Natural Science Foundation of China (grant numbers 41204111, 41574146, 41774162, and 41704155) and the China Postdoctoral Science Foundation (grant numbers $2017 \mathrm{M} 622504$ and 2019T120679). The work of Vladimir Frolov was supported through the Russian Education Ministry (project number 3.1844.2017). The UHF radar data used in this paper are available through the EISCAT Madrigal database (http://www.eiscat.se/ madrigal/). The Dynasonde data used in this research are available through the website https://dynserv.eiscat.uit.no/DD/login. php.

\section{References}

Armstrong, W. T., Massey, R., Argo, P., Carlos, R., Riggin, D., Cheung, P. Y., McCarrick, M., Stanley, J., and Wong, A. Y. (1990). Continuous measurement of stimulated electromagnetic emission spectra from $\mathrm{HF}$ excited ionospheric turbulence. Radio Sci., 25(6), 1283-1289. https://doi.org/10.1029/RS025i006p01283

Bernhardt, P. A., Selcher, C. A., and Kowtha, S. (2011). Electron and ion Bernstein waves excited in the ionosphere by high power EM waves at the second harmonic of the electron cyclotron frequency. Geophys. Res. Lett., 38(19), L19107. https://doi.org/10.1029/2011GL049390

Blagoveshchenskaya, N. F., Borisova, T. D., Yeoman, T. K., Rietveld, M. T., Ivanova, I. M., and Baddeley, L. J. (2011). Artificial small-scale field-aligned irregularities in the high-latitude $\mathrm{F}$ region of the ionosphere induced by an X-mode HF heater wave. Geophys. Res. Lett., 38(8), L08802. https://doi.org/10.1029/2011GL046724

Blagoveshchenskaya, N. F., Borisova, T. D., Kosch, M., Sergienko, T., Brändström, U., Yeoman, T. K., and Häggström, I. (2014). Optical and ionospheric phenomena at EISCAT under continuous X-mode HF pumping. J. Geophys. Res.: Space Phys., 119(12), 10483-10498. https://doi.org/10.1002/2014JA020658

Blagoveshchenskaya, N. F., Borisova, T. D., Yeoman, T. K., Häggström, l., and Kalishin, A. S. (2015). Modification of the high latitude ionosphere $F$ region by $\mathrm{X}$-mode powerful $\mathrm{HF}$ radio waves: Experimental results from multiinstrument diagnostics. J. Atmos. Sol.-Terr. Phys., 135, 50-63. https://doi.org/10.1016/j.jastp.2015.10.009

Blagoveshchenskaya, N. F., Borisova, T. D., Kalishin, A. S., Yeoman, T. K., and Haggstrom, I. (2017a). First observations of electron gyro-harmonic effects under X-mode HF pumping the high latitude ionospheric F-region. J. Atmos. Terr. Phys., 155, 36-49. https://doi.org/10.1016/j.jastp.2017.02.003

Blagoveshchenskaya, N. F., Borisova, T. D., and Yeoman, T. K. (2017b). Comment on "Parametric instability induced by X-mode wave heating at EISCAT" by Wang et al. (2016). J. Geophys. Res.: Space Phys., 122(12), 12570-12585. https://doi.org/10.1002/2017JA023880

Blagoveshchenskaya, N. F., Borisova, T. D., Kalishin, A. S., Kayatkin, V. N., Yeoman, T. K., \& HäggströM, I. (2018). Comparison of the effects induced by the ordinary (O-mode) and extraordinary (X-mode) polarized powerful HF radio waves in the high-latitude ionospheric $\mathrm{F}$ region. Cosmic Research, 56(1), 11-25. https://doi.org/10.1134/S0010952518010045

Boiko, G. N., Erukhimov, L. M., Zyuzin, V. A., Komrakov, G. P., Metelev, S. A., Mityakov, N. A., Nikonov, V. A., Ryzhov, V. A., Tokarev, Y. V., and Frolov, V. L. (1985). Dynamic characteristics of stimulated radio emission from ionospheric plasma. Radiophys. Quantum Electron., 28(4), 259-268. https://doi.org/10.1007/BF01034596

Borisov, N., Honary, F., and Li, H. (2018). Excitation of plasma irregularities in the $\mathrm{F}$ region of the ionosphere by powerful $\mathrm{HF}$ radio waves of $\mathrm{X}$-polarization. $\mathrm{J}$. Geophys. Res.: Space Phys., 123(6), 5246-5260. https://doi.org/10.1029/2018JA025530

Cheung, P. Y., Mjølhus, E., DuBois, D. F., Pau, J., Zwi, H., and Wong, A. Y. (1997). Stimulated radiation from strong Langmuir turbulence in ionospheric modification. Phys. Rev. Lett., 79(7), 1273-1276.

https://doi.org/10.1103/PhysRevLett.79.1273

Fejer, J. A., and Leer, E. (1972). Excitation of parametric instabilities by radio waves in the ionosphere. Radio Sci., 7(4), 481-491. https://doi.org/10.1029/RS007i004p00481

Frolov, V. L., Komrakov, G. P., Sergeev, E. N., Thidé, B., Waldenvik, M., and Veszelei, E. (1997). Results of the experimental study of narrow continuum features in stimulated ionospheric emission spectra. Radiophys. Quantum Electron., 40(9), 731-744. https://doi.org/10.1007/BF02676524

Frolov, V. L., Kagan, L. M., and Sergeev, E. N. (1999). Review of features of stimulated electromagnetic emission (SEE): Recent results obtained at the "Sura" heating facility. Radiophys. Quantum Electron., 42(7), 557-561. https://doi.org/10.1007/BF02677561

Frolov, V. L., Sergeev, E. N., Ermakova, E. N., Komrakov, G. P., and Stubbe, P. (2001). Spectral features of stimulated electromagnetic emission, measured in the 4.3-9.5 MHz pump wave frequency range. Geophys. Res. Lett., 28(16), 3103-3106. https://doi.org/10.1029/2001GL013251

Frolov, V. L., Sergeev, E. N., Komrakov, G. P., Stubbe, P., Thidé, B., Waldenvik, M., Veszelei, E., and Leyser, T. B. (2004). Ponderomotive narrow continuum (NCp) component in stimulated electromagnetic emission spectra. J. Geophys. Res.: Space Phys., 109(A7), A07304. https://doi.org/10.1029/2001JA005063

Frolov, V. L., Bolotin, I. A., Komrakov, G. P., Pershin, A. V., Vertogradov, G. G., Vertogradov, V. G., Kunitsyn, V. E., Padokhin, A. M., Kurbatov, G. A., Akchurin, A. D. and Zykov, E. Y. (2014). Generation of artificial ionospheric irregularities in the midlatitude ionosphere modified by high-power highfrequency X-mode radio waves. Radiophysics and Quantum Electronics, 57(6), 393-416. https://doi.org/10.1007/s11141-014-9523-8

Fu, H. Y., Scales, W. A., Bernhardt, P. A., Briczinski, S. J., Kosch, M. J., Senior, A., Rietveld, M. T., Yeoman, T. K., and Ruohoniemi, J. M. (2015). Stimulated Brillouin scattering during electron gyro-harmonic heating at EISCAT. Ann. Geophys., 33(8), 983-990. https://doi.org/10.5194/angeo-33-983-2015

Grach, S. M., and Trakhtengerts, V. Y. (1975). Parametric excitation of ionospheric irregularities extended along the magnetic field. Radiophys. Quantum Electron., 18(9), 951-957. https://doi.org/10.1007/BF01038190

Gurevich, A. V., Carlson, H. C., Medvedev, Y. V., and Zybin, K. P. (2004). Langmuir turbulence in ionospheric plasma. Plasma Phys. Rep., 30(12), 995-1005. https://doi.org/10.1134/1.1839953

Kelley, M. C., Arce, T. L., Salowey, J., Sulzer, M. P., Armstrong, W. T., Carter, M., and Duncan, L. M. (1995). Density depletions at the 10-m scale induced by the Arecibo heater. J. Geophys. Res.: Space Phys., 100(A9), 17367-17376. https://doi.org/10.1029/95JA00063

Kosch, M. J., Pedersen, T. R., Rietveld, M. T., Gustavsson, B., Grach, S. M., and Hagfors, T. (2007). Artificial optical emissions in the high-latitude thermosphere induced by powerful radio waves: An observational review. Adv. Space Res., 40(3), 365-376. https://doi.org/10.1016/j.asr.2007.02.061

Kuo, S. P. (2015). lonospheric modifications in high frequency heating experiments. Phys. Plasmas, 22(1), 012901. https://doi.org/10.1063/1.4905519

Lehtinen, M. S., and Huuskonen, A. (1996). General incoherent scatter analysis and GUISDAP. J. Atmos. Terr. Phys., 58(1-4), 435-452. https://doi.org/10.1016/0021-9169(95)00047-X

Leyser, T. B., Thidé, B., Derblom, H., Hedberg, Å., Lundborg, B., Stubbe, P., and Kopka, H. (1990). Dependence of stimulated electromagnetic emission on the ionosphere and pump wave. J. Geophys. Res.: Space Phys., 95(A10), 17233-17244. https://doi.org/10.1029/JA095iA10p17233

Leyser, T. B., Thidé, B., Waldenvik, M., Goodman, S., Frolov, V. L., Grach, S. M., Karashtin, A. N., Komrakov, G. P., and Kotik, D. S. (1993). Spectral structure of stimulated electromagnetic emissions between electron cyclotron harmonics. J. Geophys. Res.: Space Phys., 98(A10), 17597-17606. https://doi.org/10.1029/93JA01387

Leyser, T. B. (2001). Stimulated electromagnetic emissions by high-frequency electromagnetic pumping of the ionospheric plasma. Space Sci. Rev., 98(34), 223-228. https://doi.org/10.1023/A:1013875603938

Lobachevsky, L. A., Gruzdev, Y. V., Kim, V. Y., Mikhaylova, G. A., Panchenko, V. A., 
Polimatidi, V. P., Puchkov, V. A., Vaskov, V. V., Stubbe, P., and Kopka, H. (1992). Observations of ionospheric modification by the Troms $\varnothing$ heating facility with the mobile diagnostic equipment of IZMIRAN. J. Atmos. Terr. Phys., 54(1), 75-85. https://doi.org/10.1016/0021-9169(92)90086-Z

Rietveld, M. T., Kohl, H., Kopka, H., and Stubbe, P. (1993). Introduction to ionospheric heating at Tromsø-I. Experimental overview. J. Atmos. Terr. Phys., 55(4-5), 577-599. https://doi.org/10.1016/0021-9169(93)90007-L

Rietveld, M. T., Senior, A., Markkanen, J., and Westman, A. (2016). New capabilities of the upgraded EISCAT high-power HF facility. Radio Sci., 51(9), 1533-1546. https://doi.org/10.1002/2016RS006093

Robinson, T. R. (1989). The heating of the high lattitude ionosphere by high power radio waves. Phys. Rep., 179(2-3), 79-209. https://doi.org/10.1016/0370-1573(89)90005-7

Sergeev, E. N., Frolov, V. L., Grach, S. M., and Kotov, P. V. (2006). On the morphology of stimulated electromagnetic emission spectra in a wide pump wave frequency range. Adv. Space Res., 38(11), 2518-2526. https://doi.org/10.1016/j.asr.2005.02.046

Sharma, R., Kumar, A., and Kumar, R. (1993). Excitations of ion-Bernstein waves in ionospheric modification experiment. Radio Sci., 28(6), 951-957. https://doi.org/10.1029/93RS01374

Stubbe, P., Kopka, H., Thidé, B., and Derblom, H. (1984). Stimulated electromagnetic emission: A new technique to study the parametric decay instability in the ionosphere. J. Geophys. Res.: Space Phys., 89(A9), 7523-7536. https://doi.org/10.1029/JA089iA09p07523

Stubbe, P., Kopka, H., Rietveld, M. T., Frey, A., Høeg, P., Kohl, H., Nielsen, E., Rose, G., LaHoz, C., ... Holt, O. (1985). Ionospheric modification experiments with the Tromsø heating facility. J. Atmos. Terr. Phys., 47(12), 1151-1163. https://doi.org/10.1016/0021-9169(85)90085-6

Stubbe, P., Kohl, H., and Rietveld, M. T. (1992). Langmuir turbulence and ionospheric modification. J. Geophys. Res.: Space Phys., 97(A5), 6285-6297. https://doi.org/10.1029/91JA03047

Stubbe, P., Stocker, A. J., Honary, F., Robinson, T. R., and Jones, T. B. (1994). Stimulated electromagnetic emissions and anomalous $\mathrm{HF}$ wave absorption near electron gyroharmonics. J. Geophys. Res.: Space Phys., 99(A4), 6233-6246. https://doi.org/10.1029/94JA00023

Stubbe, P., and Hagfors, T. (1997). The Earth's ionosphere: A wall-less plasma laboratory. Surv. Geophys., 18(1), 57-127.

https://doi.org/10.1023/A:1006583101811

Thidé, B., Kopka, H., and Stubbe, P. (1982). Observations of stimulated scattering of a strong high-frequency radio wave in the ionosphere. Phys. Rev. Lett., 49(21), 1561-1564. https://doi.org/10.1103/PhysRevLett.49.1561

Thidé, B., Derblom, H., Hedberg, Å., Kopka, H., and Stubbe, P. (1983). Observations of stimulated electromagnetic emissions in ionospheric heating experiments. Radio Sci, 18(6), 851-859. https://doi.org/10.1029/RS018i006p00851

Thidé, B., Hedberg, A.., Fejer, J. A., and Sulzer, M. P. (1989). First observations of stimulated electromagnetic emission at Arecibo. Geophys. Res. Lett., 16(5), 369-372. https://doi.org/10.1029/GL016i005p00369

Thidé, B., Djuth, F. T., Leyser, T. B., ands lerkic, H. M. (1995). Evolution of Langmuir turbulence and stimulated electromagnetic emissions excited with a 3-mHz pump wave at Arecibo. J. Geophys. Res.: Space Phys., 100(A12), 23887-23899. https://doi.org/10.1029/95JA01631

Vickers H. (2011). Radar observations of artificial ionospheric modification effects, effects [Ph. D. thesis]. Leicester University, Leicester, UK.

Wang, X., Zhou, C., Liu, M. R., Honary, F., Ni, B. B., and Zhao, Z. Y. (2016). Parametric instability induced by $\mathrm{X}$-mode wave heating at EISCAT. J. Geophys. Res.: Space Phys., 121(10), 10536-10548. https://doi.org/10.1002/2016JA023070

Wang, X., and Zhou, C. (2017). Aspect dependence of Langmuir parametric instability excitation observed by EISCAT. Geophys. Res. Lett., 44(18), 9124-9133. https://doi.org/10.1002/2017GL074743

Wang, X., Zhou, C., and Honary, F. (2018). Reply to Comment on the article "Parametric Instability Induced by X-mode Wave Heating at EISCAT" by Wang et al. (2016). J. Geophys. Res.: Space Phys., 123(9), 8051-8061. https://doi.org/10.1029/2018JA025808 